\title{
APRESENTAÇÃO
}

\section{REPRESENTAÇÕES DO GUERREIRO, DO SÁBIO \\ E DO SOBERANO NA NARRATIVA: A FIGURA DE ALEXANDRE E OUTROS HERÓIS DA ANTIGUIDADE NA LITERATURA, NA HISTÓRIA, NAS ARTES E NO CINEMA}

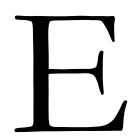

m dezembro de 2018, entre os dias 04 e 07, foi realizado o VIII Simpósio Antigos e Modernos: "Alexandre...Alexandre! Alexandre: aspectos do guerreiro, do sábio e do soberano na narrativa". O tema central do evento concernia à figura de Alexandre, de maneira particular, e às representações do soberano, do sábio e do guerreiro na narrativa, de modo mais geral. A ideia central era discutir os aspectos biográficos, históricos e literários dessas representações na Modernidade e Antiguidade, tendo como perspectiva inicial a constituição da obra mais conhecida como Romance de Alexandre, e, de forma mais ampla, refletir sobre a recepção de Alexandre e de outras figuras míticas e históricas na história, na literatura e nas artes. Tendo como base alguns desses trabalhos apresentados no Simpósio de 2018, foram reunidos no presente dossiê diversos artigos segundo um duplo enquadramento: na primeira parte, trabalhos que tematizam, de forma mais centrada e direta, o Romance de Alexandre; na segunda parte, aqueles trabalhos cuja tônica recai sobre a recepção da cultura clássica, a partir da assimilação e retomada da figura do guerreiro, do sábio e do soberano em suas interrelações nos registros da literatura, da história, das artes e, mais especificamente, do cinema.

\section{Primeira parte: ensaios sobre o Romance de Alexandre}

$\mathrm{Na}$ primeira parte, incluem-se ensaios que versam, de maneira mais centrada, sobre o Romance de Alexandre. Abre, assim, este dossiê o artigo do professor Jacyntho Lins Brandão, cuja formulação acerca da função e do emprego dos lugares comuns em fontes diversificadas na Antiguidade é o foco principal para pensar as figurações de Alexandre nos períodos antigo e medieval, mormente a partir dos konoi tópoi mais emblemáticos do Romance de Alexandre. Comenta ele os lugares comuns nessa obra, em primeiro lugar, referentes à fisionomia de Alexandre e ao seu "travestismo" assimilando traços e atributos de deuses, em segundo lugar, relativamente à refiguração da fábula esópica, Um astrólogo, na cena da morte de Nectanebo, figurado aí como pai de Alexandre. A partir desse enquadramento inicial, o autor aduz como outro argumento de seu trabalho, no intuito de encontrar uma justificativa para a grande propagação do Romance de Alexandre e suas versões no Ocidente e no Oriente, avaliar a obra na qualidade de uma "narrativa persa": a "biogeografia" de Alexandre refiguraria o sistema persa global de governo, nos moldes de um império tributário, que remontaria 
até a produção suméria e acádia, a exemplo da saga de Gilgámesh. Dessa forma, as ações de Alexandre na narrativa, dentro de uma configuração específica do tempo e do espaço, constituiriam um tipo especial de cronótopo, cuja arqueologia o estudioso intenta traçar em seus contornos mais gerais. Tomando como exemplo de caso, ele analisa duas passagens do Romance de Alexandre: a descida de Alexandre no fundo do oceano e a sua subida nos ares, buscando esboçar um quadro de elementos comuns, apontando também as singularidades, que aparecem em obras de um grande espectro temporal: o poema acádio Etana, a Epopeia de Gilgámesh, Atrahasis, assim como relatos de origem judaica, como a Gemara, além de textos medievais diversos, entre outros.

Abordando um desses tópicos, a subida de Alexandre pelos ares, Ioannis Konstantakos faz uma série de aproximações com narrativas antigas e medievais (mas que remontariam a épocas bem mais anteriores), como, por exemplo, o conto iraniano relativo à saga de Kai Kāūs e a narrativa babilônica que tem como protagonista Nimrod. Segundo o argumento desenvolvido pelo autor, o voo de Alexandre seria, em seus traços gerais, devedor da configuração da história de Kai Kāūs, uma vez que compartilham traços definidores e característicos: o herói é levado ao ar dentro de algum tipo de artefato (bolsa suspensa numa espécie de jugo, cesta ou mesmo sentado num trono) puxado por aves de rapina que, no caso de Alexandre, são atraídas por um pedaço de carne na extremidade de uma longa lança, a partir de que o herói pode direcionar o voo para cima e para baixo. Em outro ciclo de tradições de tipo similar, o herói mesopotâmico Nimrod, mencionado no Gênesis como primeiro imperador da Babilônia e, ulteriormente, conhecido por ter construído a Torre de Babel, encarna o personagem do rebelde que desafia o poder de Deus: em versões islâmicas medievais, Nimrod manda construir um caixote ou baú com uma portinhola para cima e outra para baixo, com lanças aí fincadas tendo pedaços de carne na ponta e abutres usados para fazer o voo. Konstantakos conclui como evidentes as similaridades entre essas versões orientais e a ascensão de Alexandre que, de um lado, assimilou seus traços de narrativas orientais sobre reis voadores, como a de Kai Kāūs e, de outro, influenciou as versões medievais, as quais utilizam o mesmo estratagema da isca como um expediente da máquina de voar.

No terceiro artigo, exploram-se as estratégias textuais que denunciam aspectos composicionais, diegéticos e temáticos recorrentes na narrativa. Pedro Ipiranga Júnior, consoante a isso, analisa diversas passagens do Romance de Alexandre, mais especificamente da recensão $\alpha$, a partir de três expedientes narrativos: 1) a enunciação de algum princípio ético ou filosófico, dentro de uma ambientação cênica apotegmática; 2) sinais, oráculos, sinais, seguidos de decifração ou explicação; 3) comparação do personagem de Alexandre com deuses e heróis. A partir da montagem de um quadro de passagens referentes a esses três expedientes, ele chega à conclusão de que eles estariam interconectados em rede na narrativa, constituindo uma espécie peculiar de unidade narrativa, que subsistiria em meio às diversas alterações, assimilações e incorporações de partes diferentes em versões e adaptações subsequentes.

No quarto e último trabalho dessa primeira parte, Pedro Dolabela formula uma hipótese original e inovadora sobre o Romance de Alexandre: estaria subjacente ao texto um 
princípio de "pseudoficcionalidade", próprio de obras cujo estatuto oscila entre verdade e ficção, mas que prefigura e pressupõe a ficção mais plenamente patente em outros tipos do gênero romanesco. Além disso, ele advoga a tese (defendida em estudos mais recentes, a exemplo dos scholars partícipes da obra enciclopédica de Moretti sobre romance) da poligênese do gênero romanesco e, por conseguinte, se atém a uma concepção mais ampla de romance. Em sua conclusão, o autor declara que o status epistêmico de pseudoficcionalidade do Romance de Alexandre representou uma mediação importante para a "tradicionalização da ficção", auxiliando os leitores a se acostumarem com um discurso paulatinamente mais ficcional e, assim, habituar a recepção às experimentações cada vez mais inovadoras das várias espécies romanescas.

\section{SEgunda PARTE: A RECEPÇÃo dA Figura de AleXandre E A REFiguraÇão dA ANTIGUIDADE CLÁSSICA}

Nos ensaios da segunda parte, o esforço teórico dos especialistas se volta para a recepção numa dupla visada: por um lado, recepção das formas de refiguração de Alexandre; por outro, recepção relativa às representações de heróis, de soberanos e guerreiros, de autores clássicos e da própria noção de Antiguidade Clássica em seu estatuto de paradigma. O primeiro artigo, de Renata Senna Garraffoni e José Grillo, explicita a problemática concernente às formas de interpretação de imagens e textos, as metodologias diferenciadas utilizadas e os posicionamentos teóricos da crítica mais recente. Tomam como estudo de caso o Mosaico de Alexandre pertencente à Casa do Fauno em Pompeia. Os autores partem do debate sobre a figura de Alexandre inicialmente no contexto helênico, sua recepção no período romano-helenístico subsequente e posteriormente. Sua abordagem é pautada na linha de estudos sobre cultura material, no caso, sobre fontes materiais e escritos que interferiram na forma da fisionomia de Alexandre, bem como nas refigurações e idealizações de sua imagem, tendo como foco o Mosaico de Alexandre. Os dois estudiosos trazem à tona o estado da arte em relação a este último, analisando os modos de interpretação desde estudos do século XIX até as teorias e pesquisas mais recentes, explicitando o jogo complexo entre as diferentes formas simbólicas de lidar com a arte, assim como com as diversas facetas da história que sempre se mostraria fragmentada e sujeita a múltiplos enfoques.

No ensaio seguinte, "Alexandre, o Grande, na Alexandra, de Lícofron", Roosevelt Rocha faz um comentário filológico e hermenêutico de uma passagem específica da obra Alexandra (um poema helenístico atribuído a Lícofron), os versos 1435-45, em que se mencionam as ações e desdobramentos do empreendimento de Alexandre. Trata-se, no caso, das predições de Cassandra, filha de Príamo, sobre os acontecimentos presentes, passados e futuros relativos a Troia e aos gregos. Alexandre é descrito como leão (e provavelmente a comparação com o lobo deva lhe ser atribuída); e é por intermédio de sua ação que os conflitos entre Europa e Ásia terão termo. Assim, o poema, provavelmente do século II a.C, salienta os atributos de Alexandre como pacificador, de grande guerreiro e conquistador, atributos esses já devedores da mitificação de sua figura. 
Os dois ensaios seguintes tratam da recepção da Antiguidade Clássica no século XIX: o primeiro, sob as lentes de Ferdinand Denis, explicita uma concepção de Antiguidade utilizada como um termo de comparação para a produção literária e cultural de povos autóctones; o segundo, atendo-se à produção romanesca inicial de Machado de Assis, analisa os processos de imitação e emulação próprios da poética machadiana.

Por um lado, é certo que, como fica evidenciado pelos ensaios da primeira parte, a busca de conhecimento e saber é uma característica do Romance de Alexandre que perpassa toda a narrativa em forma da exposição de máximas e de preceitos morais, mas que se revela mais claramente na seção em que o protagonista encontra, em sua aventura na Índia, sábios hindus que são chamados de brâmanes na obra. A eles, que dizem se ocupar da filosofia, dirige várias perguntas: "O que é mais forte: a morte ou a vida?"; "O que é maior: a terra ou o mar?" (Romance de Alexandre, III, 5-9). A literatura sapiencial foi um gênero bastante apreciado na Antiguidade e na Idade Média, o que, entre muitos outros fatores, contribuiu para a difusão do Romance de Alexandre e do Romance de Esopo. Por outro lado, pode-se evocar o fato curioso de que, em 1832, Ferdinand Denis, por sua vez, publicava a obra Le Brahme voyageur, ou la sagesse populaire de toutes les nations, uma ficção romanesca em que um jovem brâmane viaja pelo mundo em busca de angariar experiência e de registrar ditos e máximas de todos os povos, com o intuito de adquirir uma sabedoria mais ampla e profunda. De uma forma peculiar, Denis parecia embarcar numa narrativa patentemente sapiencial e o protagonista da obra, Nara-Mouny, qual um novo Alexandre, partia em suas viagens por todo o mundo conhecido, em busca de conhecimento e sabedoria. Denis, por seu turno, durante o período de 1816 a 1819, também enveredava numa aventura no Novo Mundo para adquirir fortuna, cuja finalidade inicial seria atingir a região da Índia, mas acabara por se fixar no Brasil neste período. Frustradas suas ambições, ele seria forçado a voltar à França, a partir de que começaria a escrever suas obras sobre o Brasil e sobre as Américas, sendo reconhecido como brasilianista e americanista. Esse olhar de viajante, conquanto não tenha ele mais se aventurado por outras terras, caracteriza toda sua produção escrita: pelos livros, relatos de viagens, informantes e peregrinos, Ferdinand Denis empreende seu périplo pelo mundo, em que o personagem do brâmane viajante não deixa de ser uma espécie de alter ego, tal qual um Alexandre ao reverso, narrativa e romanescamente.

É essa figura invulgar que enseja a discussão no artigo assinado conjuntamente por Maria Edith Maroca Avelar Rivelli de Oliveira e Pedro Ipiranga Júnior: faz-se, num primeiro momento, uma apreciação do projeto elaborado pelo erudito francês Ferdinand Denis que diz respeito, de um lado, à concepção das antiguidades nacionais românticas e, de outro, à estratégia de comparação entre antigos e "selvagens" em vista de valorizar a produção cultural e literária do Brasil. Atribuindo aos selvagens e antigos a demonstração da existência de um instinto natural para a liberdade, segundo os parâmetros da teoria da historiografia liberal francesa em que estava inserido, Denis, segundo os autores, professa em suas obras este princípio norteador da condição de liberdade para todos os povos, o que o faz denunciar seguidamente o fenômeno da escravidão em sua época. Num segundo momento, são analisados diversos excertos de obras, tanto de um gênero de escrito mais historiográfico 
e, por assim dizer, etnográfico, quanto de narrativas ficcionais e autobiográficas, para exemplificar a forma de retomada da Antiguidade Clássica, de deuses, heróis e autores clássicos, em sua comparação com índios, negros e outros povos situados pelo autor como na infância da história, assim como para evidenciar o fundamento adotado da historiografia liberal, o princípio de liberdade incondicional, na tessitura do discurso (auto)biográfico e romanesco destes textos.

Edson Martins, por sua vez, analisa a produção ficcional machadiana da década de 1870: Ressurreição (1872), A mão e a luva (1874), Helena (1876) e Iaiá Garcia (1878). Verifica, em vários trechos das obras, a forma de assimilação e refiguração de cenas e personagens dos poemas homéricos. O estudioso elenca as várias referências a autores da Antiguidade Clássica: Platão, Esopo, Aristófanes, Virgílio, Suetônio, Plutarco, César, Tertuliano, Agostinho, entre outros. Consoante a isso, a intertextualidade com a épica homérica, mormente com a Ilíada, seria patente, tanto na forma da dinâmica narrativa e da ambientação cênica, como na construção de personagens, o que resulta não numa imitação servil de modelos clássicos, mas numa apropriação emuladora, que se afiguraria, segundo Martins, como um ritual da iniciação poética e literária do jovem Machado.

Por fim, no último arquivo deste dossiê, a tônica recai novamente sobre a figura de Alexandre, mais precisamente, sobre as representações de Aristóteles em sua relação pedagógica com Alexandre, enfocado, assim, na qualidade de discípulo. Tendo como corpus de análise os filmes: Sikandar (1941, Índia), de Sohrab Modi, Alexandre o Grande (1956), de Robert Rossen, e Alexandre (2004), de Oliver Stone, Maria Cecília de Miranda Nogueira Coelho desenvolve, num ensaio bastante ilustrativo e provocador, a constituição da imagem de Alexandre nestes filmes em sua associação e intrínseca relação com as atitudes e a forma de agir do filósofo. Em sua conclusão, a autora adverte que, embora seja inerente o perigo nas relações e aproximações entre história e ficção, bem como entre filosofia e política, ambas visadas nas relações entre Aristóteles e Alexandre, umas e outras devem ser discutidas, evidenciadas e avaliadas, como fontes de pesquisa e de uma contínua aprendizagem.

Gostaríamos de agradecer a todos os especialistas que aceitaram o convite para participar do presente dossiê, assim como às diversas unidades da Universidade Federal do Paraná que propiciaram os recursos e o apoio para a realização do "VIII Simpósio Antigos e Modernos": o Departamento de Polonês, Alemão e Letras Clássicas, o Departamento de História, o Programa de Pós-Graduação em Letras, o Programa de Pós-Graduação em História e o Setor de Ciências Humanas da UFPR.

Bernardo Brandão, Pedro Ipiranga Júnior, Renata Senna Garraffoni, os organizadores. 